\title{
DEBATES
}

\section{Agir pelo jornalismo: do engajamento profissional à "defesa intransigente dos direitos humanos"}

\author{
Acting for journalism: from the professional engagement to the \\ "intransigent defense of human rights"
}

\section{João Gilberto do Nascimento Lima}

\section{Resumo}

O presente artigo insere-se na problemática da internacionalização de espaços e saberes profissionais, partindo do caso de uma ONG de jornalistas "investigativas" que associa o engajamento profissional à defesa de causas tais como a dos "direitos humanos". Explorando principalmente um conjunto de entrevistas realizadas com as fundadoras da ONG, busca-se: 1) descrever as suas respectivas relaçóes com a "profissão", o "social" e a "política" e identificar as intençóes e os processos que levaram à criação da ONG; 2) demonstrar os modos pelos quais as múltiplas ligaçóes com o "internacional" (estudos no exterior, financiamento por fundaçóes filantrópicas, participação em "grandes investigaçóes" transnacionais) contribuem para a configuração de um modelo relativamente novo de atuação profissional, bem como para a reestruturação do espaço jornalístico brasileiro no período recente.

\section{Palavras-chave}

Internacionalização; Jornalismo Investigativo; Direitos Humanos; Engajamento.

\begin{abstract}
The present article introduces the problem of the internationalization of spaces and professional knowledge, starting from the case of an NGO of "investigative" journalists that associates professional engagement to the defense of causes such as "human rights". Exploring mainly a set of interviews performed with the founders of the NGO, it seeks to: 1) describe their respective relations with the "profession", the "social" and "politics", and to identify the intentions and processes that led to the creation of the NGO; 2) demonstrate the ways by which the multiple connections with the "international" (studies abroad, funding by philanthropic foundations, participation in "large transnational investigations") contribute to the configuration of a relatively new model of professional performance, as well as for the restructuring of the Brazilian journalistic space in the recent period.
\end{abstract}

\section{Keywords}

Internationalization; Investigative Journalism; Human Rights; Commitment. 


\section{Introdução}

A relação do espaço jornalístico com outros universos sociais é relativamente bem explorada pela bibliografia (BOURDIEU, 1997 e 2007; CHAMPAGNE, 1996, 2007 e 2016; MARCHETTI, 2001, 2002 e 2010; CHUPIN e NOLLET, 2006). No caso do jornalismo investigativo, a sua emergência é frequentemente explicada não apenas por transformaçôes internas ao espaço profissional, mas também externas, com ênfase para os espaços político e jurídico (GARRAUD, 1999; MARCHETTI, 2001).

No caso brasileiro, a bibliografia especializada aponta o desenvolvimento mais sistemático do jornalismo investigativo no Brasil após a redemocratização e, particularmente, com o impeachment de Fernando Collor de Melo. Com maior liberdade e autonomia em relação à política, os jornalistas teriam tido então maiores condiçôes de fugir do noticiário oficial e desenvolver investigaçóes de maior fôlego sobre assuntos variados ${ }^{1}$ (FORTES, 2005; SEQUEIRA, 2005; MATOS, 2008). Essas mudanças nos espaços político e jornalístico são acompanhadas também por mudanças significativas no espaço jurídico, inaugurando-se novos usos do direito ${ }^{2}$ (ENGELMANN, 2006a e 2006b).

Entendendo os jornalistas como "produtores de crítica" engajados em "empresas de denúncia” diversas (BRIQUET e GARRAUD, 2001), o objetivo deste texto é abordar algumas destas mudanças mais recentes, buscando relacionar o fenômeno da internacionalização do "jornalismo investigativo" com padróes de atuação profissional marcados pela tradução causas "sociais" e/ou "políticas" para o espaço jornalístico (principalmente aquelas relacionadas, de modo geral, aos "direitos humanos") por meio de ONGs jornalísticas. Pretende-se demonstrar como o ativismo profissional e seu enfoque em pautas "sociais" associado ao investimento em ONGs jornalísticas se constitui progressivamente numa das formas privilegiadas de relações com organismos estrangeiros (fundaçôes filantrópicas, outras ONGs, jornalísticas ou não etc.) e de construção de carreiras internacionais (notadamente por meio da participação em "investigações" transnacionais, baseadas geralmente em "grandes vazamentos").

\footnotetext{
1 As relaçôes do "jornalismo cão-de-guarda" (denominação muitas vezes usada como sinônima à de “jornalismo investigativo") com processos de democratização também são apontadas para o caso de outros países da América Latina (ALVES, 2005).

2 Para uma análise específica das relações entre jornalistas e o Ministério Público na produção de “denúncias" ou "dossiês", ver Nascimento (2010).
} 
Está em jogo, portanto, de um lado, as possibilidades de politização (LAGROYE, 2003) da condição profissional e a pluralidade dos engajamentos possíveis (CHAMPY e ISRAËL, 2009; LÉVÊQUE, 2010) e, de outro, a promoção e cooperação em torno de "causas" (inclusive da própria causa profissional) internacionalmente reconhecidas como legítimas ${ }^{3}$.

Toma-se por objeto privilegiado de análise o caso da Agência Pública de Jornalismo Investigativo, uma ONG que se define como "a primeira agência de jornalismo investigativo sem fins lucrativos do país”. Este é um caso representativo de uma série de tendências que se sobrepóem no espaço jornalístico brasileiro no período recente $e^{4}$.

Partindo principalmente da sociografia de "agentes do internacional" (DEZALAY e MADSEN, 2013), o texto divide-se em quatro momentos: primeiramente, serão apresentados e discutidos alguns elementos mais gerais relativos às concepçôes "alternativas" e "independentes" sobre a profissão das três fundadoras da ONG. Em seguida, são cotejadas as trajetórias sociais e profissionais das jornalistas. No terceiro momento, centrando a atenção em um dos casos, analiza-se os mecanismos de construção de um capital internacional (WAGNER e RÉAU, 2015) e a importação de um modelo profissional, o do jornalismo investigativo sem fins lucrativos. Por fim, entra em pauta a criação da Agência e a sua relação com tendências recentes que se observam na profissão jornalística, tanto nacional quanto internacionalmente.

\section{O contato com um jornalismo "contra-hegemônico"}

Os autores que se dedicam ao estudo da profissão jornalística frequentemente salientam a centralidade das redes de relações estabelecidas dentro das redaçóes para o desenrolar das carreiras (MARCHETTI, 2002 e 2010; PETRARCA, 2007), em particular por se tratar de uma profissão pouco institucionalizada, onde os "convites" e "indicaçôes" são estruturantes dos modos de recrutamento profissional. Para o caso em pauta, essa importância é ainda maior, tendo em vista o caráter relativamente

\footnotetext{
3 Para o caso específico dos "direitos humanos", Dezalay e Garth (2002) mostram como a sua promoção internacional é objeto de lutas simbólicas e de afrontamentos políticos entre grupos profissionais.

${ }^{4}$ Os materiais aqui explorados são em grande parte oriundos do aproveitamento parcial de entrevistas junto aos profissionais que compóem a Agência, que foram realizadas durante pesquisa de campo na sua sede, em São Paulo, entre o final de 2015 e início de 2016. A todos eles, registro aqui meu agradecimento.
} 
estreito e a densidade da rede que permite as jornalistas em questão circular pelo espaço profissional. As suas respectivas trajetórias foram marcadas pela passagem - em diferentes momentos de suas carreiras - por um mesmo veículo, a revista Caros Amigos. Este veículo guarda algumas especificidades em relação ao conjunto da imprensa brasileira do final dos anos 1990 e primeira década dos anos 2000, as quais cumpre sumariamente destacar.

Fundada em abril de $1997^{5}$, em Sáo Paulo, a revista surgiu a partir de discussóes travadas por "um grupo de amigos, que incluía jornalistas, publicitários, profissionais liberais, profissionais da comunicação" que desejava "criar um veículo que se contrapusesse ao jornalismo predominante", tanto em termos de linha editorial quanto nas formas de financiamento e gestão. Buscavam com isso trazer de volta o "texto de qualidade" e, em suma, incarnar os "valores essenciais do jornalismo". Parte dos jornalistas envolvidos no "projeto" de criação de Caros Amigos já havia trabalhado conjuntamente em outras redaçóes e veículos, com destaque para a revista Realidade $^{7}$ e alguns jornais da chamada "imprensa alternativa" ${ }^{8}$. Em entrevista a Pereira Filho (2004, p. 28), Marina Amaral, à época repórter de Caros Amigos - e uma das fundadoras da ONG Pública - considerava que a influência da "imprensa alternativa" da revista teria se dado "de uma maneira muito orgânica, porque pessoas que fizeram parte de diversos projetos criaram laços e continuaram juntas. Essas

\footnotetext{
${ }^{5}$ A revista encerrou suas atividades em 2017, devido a problemas financeiros.

${ }^{6}$ Para uma discussáo sobre a generalidade da estratégia de "retorno às fontes" que se encontra na origem de todas as tentativas de subversões heréticas, ver Bourdieu (2006). Lévêque (2010, p. 10) também chama a atenção para essas estratégias no caso do jornalismo, que são principalmente fruto da iniciativa de profissionais "críticos". Sobre a oposição entre veículos "estabelecidos" e outsiders no jornalismo, ver Néveu (2006).

7 Publicação inaugurada em 1966, pela editora Abril. Encerrou suas atividades em 1976. Chegou a vender 500 mil exemplares por edição, sendo assim considerada como um "fenômeno editorial" para aquele período. É reconhecida no meio profissional como um dos abrigos da excelência da reportagem no Brasil, sendo constantemente lembrada e celebrada como um dos "ninhos" dos melhores repórteres brasileiros (SOUZA, 2010). Pereira Filho (2004), inscreve explicitamente a experiência e o legado de Realidade no "projeto" de Caros Amigos, sendo esta "herança” ela mesma reivindicada, em maior ou menor grau, pelos próprios jornalistas da então emergente publicação.

${ }^{8}$ Para uma visão mais geral sobre o conjunto da produção "alternativa”, ver Kucinski (1991). Pereira Filho (2004, p. 26) considera que Caros Amigos "resgata a vertente alternativa e de independência do jornalismo brasileiro, dentro de uma perspectiva criativa, ativa e renovadora”. Ferron (2006) alerta para os perigos que uma análise irrefletida com base da categoria de "mídia alternativa” engendram, que envolvem inclusive possíveis usos das interpretaçóes acadêmicas nas lutas de legitimação que se desenrolam no espaço jornalístico entre "tradicionais" e "alternativos".
} 
pessoas trouxeram essa bagagem (...) É um jornalismo alternativo, no sentido de contra-hegemônico".

O principal artífice da publicação foi o seu editor-chefe, o jornalista Sérgio de Souza, proprietário da editora Casa Amarela que, entre o conjunto das suas publicações, tinha em Caros Amigos o seu "carro-chefe". "Serjão", como era conhecido no meio jornalístico, iniciou sua carreira no jornalismo no final dos anos 1950, na Folha de S. Paulo, migrando para a revista Quatro Rodas, da editora Abril, alguns anos mais tarde. Na editora, participou da equipe que criou a revista Realidade, onde ocupou a função de editor. Durante a ditadura, foi proprietário de uma editora que foi responsável pelo lançamento de algumas publicações do "cenário alternativo" da época. Neste mesmo período, esteve próximo da organização política de esquerda Ação Popular (KUCINSKI, 1991, p. 38). Passou ainda pela Globo e Bandeirantes, entre outras emissoras. Tinha o sonho de fazer uma "revista de esquerda, de alto nível”. A ele é imputada a preocupação com o texto, tendo sido um dos responsáveis, em Realidade, por resgatar o "tratamento literário" na reportagem?. Considerado por alguns como um "mártir do jornalismo brasileiro", faleceu em 2008, "de pobreza" (RIBEIRO, 2018, s/p), não sem antes promover, pela Caros Amigos, duas edições do "Anticurso Caros Amigos: como não enriquecer na profissão".

É possível afirmar que Caros Amigos se constituiu, no final dos anos 1990 e início dos 2000, como um "pólo de atração" para jovens estudantes de jornalismo interessados na cobertura de pautas "sociais" e de "direitos humanos", juntamente com a revista Carta Capital ${ }^{10}$. Esses dois veículos são frequentemente identificados com posições mais à "esquerda" ${ }^{11}$ " e, mais especificamente, ao Partido dos

\footnotetext{
9 Pereira Filho (2004) identifica a influência do New Journalism sobre a publicação. Surgido nos Estados Unidos por volta dos anos 1960, o New Journalism é uma vertente que ficou conhecida por inserir o repórter no relato e pela sua proximidade com a escrita literária. Para Hunter (1997), esta corrente estabeleceu alguns princípios que seriam retomados pela "revolução investigativa" no jornalismo norte-americano.

${ }^{10}$ Revista fundada em 1994 por Mino Carta.

${ }^{11}$ Apesar de, ainda no final dos anos 1990, a publicação reivindicar para si o fato de não ser nem de “direita”, nem de "esquerda” (PEREIRA FILHO, 2004, p. 26), anos após a sua criaçáo, Caros Amigos adotou o slogan "a primeira à esquerda".
} 
Trabalhadores $(\mathrm{PT})^{12}$ e determinados movimentos sociais (com destaque para o MST).

A experiência da Caros Amigos se aproxima em muitos aspectos daquilo que analisa Hubé (2010), para o caso de dois outros veículos "alternativos". O anticonformismo, a recusa de qualquer forma de autoridade, o desejo de criar uma imprensa de "esquerda" são elementos constitutivos de Caros Amigos. De igual modo, os dilemas relativos à organização e profissionalização das empresas jornalísticas "alternativas" engendram não raro uma série de desafios, como a preocupação de não perder a "alma da publicação" ao passo que ela cresce comercialmente, ou as mudanças relativas à centralização do processo decisional, com a instituição de uma direção de redação, que vai de encontro aos princípios políticos de autogestão (HUBÉ, 2010, p. 92-93).

No caso da redação de Caros Amigos, é reconhecido no meio profissional o modo "transgressor" com que funcionava a redação da revista, baseado nas críticas aos formatos redacionais mais "tradicionais" da "grande imprensa". Mesmo que Sérgio de Souza fosse o "centro da redação", o "coração pulsante do projeto de Caros Amigos" (PEREIRA FILHO, 2004, p.109), essa centralidade não era rígida, tudo se passando como se a redação fosse um espaço informal de "troca de ideias", de "cooperação" entre todos os que dela faziam parte, conformando a representação de um "coletivo" tão paritário quanto possível. Em suma, o que aí estava em jogo era se dotar de uma estrutura organizacional que estivesse de acordo com os seus princípios políticos (HUBÉ, 2010).

É a esse meio politizado, intelectualizado, "desinteressado ${ }^{13}$ " e "crítico" dos padróes sociais e profissionais, onde engajamento político e excelência jornalística pretensamente se combinavam ${ }^{14}$, que as jornalistas fundadoras da Agência Pública atribuem a aquisição da maior parte das suas concepções profissionais, e mais do que

\footnotetext{
${ }^{12}$ Isto não quer dizer que essa identificação "partidária” não tenha sido alvo de críticas e controvérsias internas às próprias publicaçóes. No caso específico de Caros Amigos, a suposta relação com o PT foi contestada pelo próprio Sérgio de Souza e foi um dos principais motivos para a ruptura pessoal e profissional de Roberto Freire com a revista e com Sérgio de Souza, amigo até entấo de longa data (PEREIRA FILHO, 2004).

${ }^{13}$ No sentido de recusa do lucro econômico. Para uma análise das lutas que opóem produtores de produtos de uma mesma espécie entre posições "comerciais" e "não-comerciais", ver Bourdieu (2006). ${ }^{14}$ Para discussóes sobre a situação de double bind na qual frequentemente se encontram os veículos jornalísticos "alternativos" entre, de um lado, sua vontade de produzir um discurso heterodoxo sobre o mundo social e, de outro, a busca de uma autonomia relativa (tanto material quanto simbólica) na sua produção, ver os trabalhos de Ferron (2006 e 2010).
} 
isso: em grande medida, o desenrolar das suas carreiras posteriormente às suas respectivas passagens por Caros Amigos dependeu em algum grau das relaçóes tecidas no interior da revista (ou, de modo mais amplo, da rede de profissionais que orbitavam o "projeto" da publicação). Como será possível observar a partir do exame das trajetórias, as disposições "sociais" e "políticas" adquiridas em diferentes momentos também cumpriram papel importante nas escolhas e destinos profissionais.

\section{As mulheres da ONG}

A primeira das mulheres que fundaram a agência é Marina Amaral, a jornalista mais velha do conjunto de profissionais que integram a Agência Pública, com 57 anos à época da entrevista. É diretora da ONG. Oriunda de uma família de "classe média alta" de São Paulo, é filha de pai advogado formado pela USP, em 1957 - dono do seu prórpio escritório de advocacia na cidade - e de mãe secretária. Estudou em colégios particulares "tradicionais" da capital paulista: o primeiro deles, o Madre Alix ("um colégio católico de freiras pra meninas bem nascidas"), no primário e no ginásio, e, posteriormente, no Colégio Santa Cruz ("um colégio da elite liberal"), no ensino médio. Participou do movimento estudantil no final dos anos 1970 (final do seu ensino médio e início da sua primeira graduação, em Administração, na FGV, que não chegou a concluir), em São Paulo, embora nunca tenha exercido nenhuma função de liderança no mesmo. Além disso, foi simpatizante do PT na juventude, sem nunca se filiar ao partido, e participou ainda das manifestaçóes das "Diretas Já".

Formada em jornalismo pela PUC-SP em 1992 (tendo entrado no curso em 1981 e requerido seu diploma junto à instituição apenas em 2002), Marina ainda cursou Administração, na FGV (como mencionado acima), e Letras, na USP, não tendo concluído estes últimos. Após desistir do curso de Administração, e antes de ingressar no curso de Jornalismo, Marina Amaral viajou para a Europa, morando um ano e meio entre a Suíça e a França. Ao regressar do exterior, entra ao mesmo tempo nas faculdades de Jornalismo e Letras, em 1980, e alega que escolheu o jornalismo como profissão porque "gostava de escrever" e se "interessava pelas histórias das pessoas".

Ingressou na profissáo no ano de 1983 (portanto, ainda durante os estudos universitários) na Folha de S. Paulo, onde ocupou funções de edição e revisão. Nesse 
jornal, Marina Amaral conheceu Renato Ribeiro Pompeu ${ }^{15}$, um primo distante, que foi importante no seu destino profissional posterior à Folha. Saiu desse jornal em meio a questôes pessoais e, por indicação de seu primo, conheceu alguns jornalistas mais velhos, que haviam participado, por exemplo, da criação da revista Realidade e, entre eles, estava Sérgio de Souza. Marina se declara "pupila” desses jornalistas, e considera que, a partir do conhecimento destes profissionais, sua carreira jornalística "decolou".

Foi então trabalhar na TV Record, como repórter de vídeo, a convite de um ex-chefe de reportagem da Folha. Após isso, trabalhou na revista Globo Rural, que tinha como diretor de redação Sérgio de Souza, e lá afirma ter aprendido, com "Serjão", que "pode se fazer jornalismo investigativo em todo e qualquer veículo que você tiver”. Posteriormente, em 1997, Marina Amaral vai trabalhar como repórter da revista Caros Amigos, que havia sido recém-fundada por Sérgio de Souza. Anos depois, assumiu a função de editora na revista. Nela permaneceu até o ano de 2007. Desta publicação, chegou a ser sócia.

Observa-se o peso da passagem por redações jornalísticas nos (re)direcionamentos da carreira, como já destacado no item anterior. As redaçôes jornalísticas são lugares exemplares da formação de um capital de relações (com outros jornalistas, mas também com fontes) que pode possibilitar a ampliação do leque das ocupaçôes profissionais possíveis, algo que também será possível observar em outros trajetos aqui descritos. No caso de Marina Amaral, o contato com os jornalistas Renato Pompeu e Sérgio de Souza mostraram-se fundamentais, não apenas para o aprendizado de técnicas específicas próprias ao métier, mas também para a formação de concepções acerca da profissão ("jornalismo investigativo se faz em qualquer lugar", ou ainda "o jornalismo sempre foi investigativo, ou não é jornalismo").

Natalia Viana Rodrigues é, assim como Marina Amaral, diretora da Agência Pública, e faz parte de uma "geração" mais jovem de profissionais, tendo 36 anos na ocasião da entrevista. Nascida e criada em São Paulo, provém de uma família de classe média, com pai engenheiro sanitarista formado pela USP e mãe vendedora. Estudou em escola pública na educação fundamental, e migrou para o colégio

\footnotetext{
${ }^{15}$ Iniciou sua atividade profissional no jornal Folha da Manhã. Em 1965, participou da equipe de fundação do Jornal da Tarde, de São Paulo, e em 1968 da equipe de fundação da revista Veja, onde ficou até 1981. Colaborou com veículos da “imprensa alternativa” e com a própria Caros Amigos. É autor de livros, ganhador de três prêmios Abril e um prêmio Esso.
} 
Oswald de Andrade, particular, no ensino médio, juntamente com suas duas irmãs, uma doutora em sociologia pela USP e professora da FGV, e a outra, uma "artista" que reside em Pernambuco.

A passagem pelo colégio Oswald de Andrade foi relevante no seu percurso social e profissional, assim como no de suas irmâs. Com pais "tucanos" e imersa em um ambiente familiar onde não se falava muito de "política", o contato mais sistemático com discussóes dessa ordem se deu no Oswald de Andrade, que era um colégio "mais politizado" e "bastante liberal, bastante puxado pras humanidades e pro pensamento crítico", e que contribuiu para que a jornalista em questáo e suas irmás acabassem "virando pessoas meio de esquerda ${ }^{16}$, meio malucas", que não fazem "nada por dinheiro". Ainda se referindo a si e às irmãs, diz: "sociologia pela sociologia, a arte pela arte, o jornalismo pelo jornalismo".

Seu primeiro envolvimento com atividades relacionadas ao jornalismo foi no Oswald de Andrade, onde criou um "jornalzinho". Entrou nos cursos de Jornalismo, na PUC-SP (concluído em 2001), e História, na USP (inconcluso). Ainda durante a faculdade de Jornalismo, trabalhou na assessoria de comunicaçáo da universidade e, em seguida, viajou para Londres, em 2000, para aprender a falar inglês, e voltou para o Brasil fazendo "freelas". Em 2002, foi estagiária do portal Terra e, nesse mesmo ano, entrou como repórter na revista Caros Amigos - um veículo que, segundo ela, "mantinha os valores essenciais do jornalismo" -, onde ficou por quatro anos. O desejo de trabalhar com formatos ao mesmo tempo "alternativos" e "independentes" de atuação profissional por parte de Viana encontrou em Caros Amigos um lugar particularmente propício para se desenvolver.

As posições críticas em relação ao modelo "tradicional" de produção de notícias, que bem se podia observar no caso dos profissionais que criaram a Caros Amigos, também fazem parte do repertório de Natalia Viana para defender a causa profissional. De igual modo, entra em pauta um ideal de "transformação" (tanto do jornalismo quanto da "realidade brasileira"), que é frequente entre muitos dos jornalistas considerados "investigativos", ou seja, uma intervenção na realidade por meio da atividade profissional ${ }^{17}$.

\footnotetext{
${ }^{16}$ Hunter (1997) e Marchetti (2001) já observaram a recorrência da presença de disposiçóes políticas mais situadas à "esquerda" no espectro político nos perfis dos jornalistas que se dedicam a "investigações".

${ }^{17}$ Inclusive, um dos indicadores frequentemente elencados para qualificar uma produçáo jornalística como "investigativa" é se ela contribuiu ou não para mudar o fenômeno investigado a partir das
} 
A última dentre as três jornalistas em questão que participou da fundação da Agência passou pela redação da Caros Amigos após a saída de Marina Amaral e Natalia Viana. Portanto, não dividiu o ambiente desta redação com as duas. Mesmo assim, seu trajeto profissional se desenrola em meio a um conjunto de relações comum.

Nascida em São Paulo, Tatiana Merlino Dias de Almeida passou o início da infância em Santos (cidade dos seus pais), retornando para a capital paulista em seguida. Se define como sendo de uma família de "classe média mais conservadora", com pai delegado de polícia e máe formada em Letras e artista plástica. Foi educada em colégios particulares bem conceituados, e morava numa região nobre da capital paulista.

Seu interesse por política, jornalismo e questôes relativas aos direitos humanos iniciou na adolescência, quando começou a tomar contato com a história do seu tio, Luiz Eduardo Merlino, jovem jornalista militante de esquerda que foi capturado, torturado e morto por militares, em $1971^{18}$ - era o seu "herói da adolescência". Embora não tenha conhecido pessoalmente o seu tio (nasceu em 1976), a jornalista define o contato com esse acontecimento familiar como "absolutamente determinante", pois a fez "questionar muita coisa”. A partir daí, passou a frequentar reuniôes do PT e da Comissão de familiares de mortos e desaparecidos políticos, pois queria "resgatar a militância" do seu tio, queria "ver como seria ser uma militante àquela época”. A própria escolha da profissão foi inspirada no seu tio.

Em 1998, após trancar dois cursos universitários (Publicidade e Propaganda, na FAAP, e História, na USP), decidiu partir para a Inglaterra, onde morou um ano e fez cursos de inglês e literatura. No seu retorno ao Brasil, se torna professora de inglês e discente do curso de jornalismo da Cásper Líbero, que é concluído em 2005. O ambiente universitário, somado à experiência familiar relacionada ao período militar, foi determinante para os rumos da carreira. Desejava fazer jornalismo de revista, e, particularmente, trabalhar na Caros Amigos.

Um dos seus professores era José Arbex Jr., então editor da revista Caros Amigos, que anunciou na faculdade que, com a vitória de Luiz Inácio Lula da Silva para a presidência da República, em 2002, alguns movimentos sociais (entre eles, o

\footnotetext{
"revelaçóes" e/ou "denúncias" que foi capaz de fazer. Sobre o "realismo" como uma característica mais geral presente entre os intelectuais brasileiros, ver Pécaut (1990) e Coradini (1998).

${ }^{18}$ Para maiores detalhes sobre o caso, ver Merlino (2011). Sobre a atuação de Luiz Merlino em jornais da "imprensa alternativa", ver Kucinski (1991).
} 
MST) estavam se organizando para produzir um "jornal dos movimentos sociais" e "de esquerda". O jornal em questão é o Brasil de Fato, que foi lançado durante o Fórum Social Mundial de 2003, realizado em Porto Alegre ${ }^{19}$. José Arbex Jr. foi o primeiro editor do jornal, e buscou recrutar estudantes para a composição inicial do veículo. Dado o seu interesse e envolvimento com questôes "sociais" e, de modo mais geral, com a "política", Tatiana Merlino manifestou sua vontade de trabalhar no jornal recém-criado para o seu então professor. Assim, ingressou no veículo, onde permaneceu por sete anos, como repórter e editora, sempre cobrindo pautas relacionadas majoritariamente aos direitos humanos. Nele, estreitou suas relaçóes com movimentos sociais diversos, e, principalmente, com o MST, do qual se tornou uma "apoiadora"20.

Em 2010, migra para a Caros Amigos, como repórter especial e editora, quando Marina Amaral e Natalia Viana já haviam deixado o veículo. No entanto, estas últimas acompanhavam o trabalho de Merlino na revista, e, após uma série de contatos sucessivos, a convidaram para montar o projeto da Pública, onde permaneceu apenas por alguns meses, saindo da ONG por "divergências editoriais".

Definindo-se como uma "militante do direito à memória e à verdade", após sua passagem por Caros Amigos trabalhou na Comissão da Verdade do estado de São Paulo, e agora integra a Ponte Jornalismo, veículo "incubado 21 " pela Agência Pública e especializado na cobertura de violaçôes dos direitos humanos e segurança pública. Cabe ainda destacar que mesmo este último caso, em que a conciliação entre o engajamento político e a atividade jornalística parace bem estabelecida, ainda evidencia o quão delicado é o trabalho de gestão das identidades profissional e militante no jornalismo investigativo, uma vez que, em entrevista, observa-se a reticência em professar as "causas" pelas quais as jornalistas da agência atuam. Geralmente, a afirmação da condição engajada vem acompanhada, sem que essa

\footnotetext{
${ }^{19}$ José Arbex Jr., inclusive ressalta a própria relação e similitude da Caros Amigos com o Fórum Social Mundial: “(...) Caros Amigos é muito a cara do Fórum Social Mundial de Porto Alegre, é uma espécie de versão impressa do Fórum. Tem vários colaboradores e articulistas da revista de quem eu discordo completamente, inclusive daquilo que escrevem. Mas acho que é importante serem colaboradores, porque eles partem do mesmo 'ethos'. Eles têm um tipo de preocupação que é a preocupação com o Brasil, com os destinos da nação, com relações de camaradagem, de solidariedade, de respeito às diferenças e franqueza na hora de expor essas divergências" (PEREIRA FILHO, 2004, p. 119).

${ }^{20}$ Para uma análise das relaçóes entre "mídias alternativas" e movimentos sociais, com as primeiras fazendo parte dos repertórios de ação dos segundos, ver Ferron (2010).

${ }^{21}$ Diz-se do processo de apoio institucional para o começo das atividades de uma empresa, veículo etc.
} 
questão seja colocada pelo pesquisador, de um contraponto: o quanto isso não interfere na atuação jornalística, na "isenção" ou na "objetividade".

\section{A "descoberta" do jornalismo non-profit e do "mundo das ONGs"}

Devido aos seus contornos tênues e fronteiras móveis, o jornalismo pode ser considerado como um mundo em “crise perpétua" (LÉVÊQUE, 2010, p. 10). Nessa linha, atualmente é bastante difundida, dentro e fora do Brasil, a constatação da "crise" do modelo de negócios do jornalismo. Alguns trabalhos e levantamentos recentes têm tentado dar conta de mapear a extensão e características dessa "crise" e apontar alternativas. Uma delas gira em torno do desenvolvimento de um modelo que se encontra em expansão em vários países: o jornalismo "sem fins lucrativos", que em grande parte é encabeçado por veículos de pequeno porte e voltados para temáticas específicas (KAPLAN, 2013; SIMÃO, 2015; PAULINO e XAVIER, 2015; DEMENECK, 2016; BENSON, 2018). Este modelo seria uma resposta aos desafios impostos pela queda das receitas de publicidade dos veículos "tradicionais", o que estaria levando a demissóes em massa de profissionais, e mesmo ao encerramento das atividades de empresas jornalísticas.

No caso específico do jornalismo investigativo, cujos custos de produção são tendencialmente mais elevados, o modelo "sem fins lucrativos" apresenta uma recente e clara tendência de crescimento. Segundo o relatório de Kaplan (2013), a maior parte das organizações de jornalismo investigativo sem fins lucrativos nos EUA surgiram após a crise de 2008, que também afetou a indústria jornalística naquele país. Para o caso brasileiro, esse mesmo relatório (segundo a sua metodologia específica) identifica três organizaçóes sem fins lucrativos voltadas prioritariamente para a produção ou treinamento profissional: a Agência Pública, a Ponte Jornalismo e a ABRAJI (Associação Brasileira de Jornalismo Investigativo) ${ }^{22}$.

\footnotetext{
${ }^{22}$ Primeira non-profit voltada para o jornalismo investigativo no país, a ABRAJI foi criada em 2002 após o assassinato do jornalista Tim Lopes. Após a sua morte, foram organizados alguns seminários onde se discutiu a necessidade de uma entidade que melhor preparasse os jornalistas para coberturas de risco. Os seminários foram financiados com recursos do Knight Center for the Journalism in the Americas, criado um dia antes da morte de Tim Lopes, por Rosental Calmon Alves (ex-jornalista do Jornal do Brasil, atual diretor do Knight Center e professor da Universidade do Texas, em Austin, além de atual membro do conselho consultivo da Agência Pública) a partir de um grant de US\$ 2 milhões da John S. and James L. Knight Foundation. O modelo de entidade que era buscado se inspirava no da Investigative Reporters and Editors, dos Estados Unidos, que também foi criada após o assassinato de um jornalista (HUNTER, 1997; SCHUDSON, 2010). A IRE é responsável pela
} 
No modelo non-profit, a base principal dos financiamentos são os grants de fundações filantrópicas ${ }^{23}$, que trazem nos seus programas a preocupação de difundir e fomentar o jornalismo investigativo e independente, visando melhorar a "qualidade da democracia" assim como promover os valores da "transparência", a defesa dos "direitos humanos" ${ }^{24 "}$, e assim por diante.

Sem poder aprofundar neste texto as diversas lógicas dos financiamentos baseados na filantropia, assim como os dilemas e discussóes sobre a "independência" que se colocam a partir daín (SIMÃO, 2015; PAULINO e XAVIER, 2015; DEMENECK, 2016; ASSIS et al., 2017), é preciso destacar que a ampliação massiva desse novo nicho de financiamento tende a intensificar a concorrência no meio profissional pelos grants das fundações, assim como a difundir concepções "empreendedoras" no jornalismo ${ }^{26}$, o que faz com que se espere cada vez mais dos profissionais competências voltadas para a gestão e fundraising, e não apenas aquelas voltadas para a produção jornalística em si (cultivo de fontes, apuração, etc.).

É com esse modelo non-profit e com o "mundo das ONGs" que a jornalista Natalia Viana passa a ter contato na sua segunda ida a Londres, em 2006, logo após a sua saída da Caros Amigos. Desta vez, Viana partiu para fazer uma pós-graduação em Radiojornalismo no Goldsmith College, na Universidade de Londres, com uma bolsa do British Council (concluída em 2008). Nesse período, foi correspondente internacional da Bandnews e, além disso, trabalhou em parceria com diversas ONGs internacionais de jornalismo, tais como o Center for Investigative Journalism (onde

definição mais difundida e coletivamente aceita sobre o que constituiria o jornalismo investigativo (NASCIMENTO, 2010).

${ }^{23}$ Além das doaçóes de fundaçóes, o crowfunding (ou financiamento coletivo) tem sido uma outra forma, ainda secundária, por meio da qual os veículos "independentes” tem buscado angariar fundos para a produção de reportagens.

${ }^{24}$ Para uma análise do papel da filantropia (como destaque para a Fundação Ford) no apoio e fomento de movimentos ligados aos direitos humanos na América Latina, ver Dezalay e Garth (2002). Sobre o gerenciamento de fundos internacionais que visam a promoção dos direitos humanos, ver Guilhot (2003).

25 Benson (2018), por exemplo, destaca que as exigências que as fundaçóes fazem às organizaçóes jornalísticas sem fins lucrativos para que estas tenham, ao mesmo tempo, "sustentabilidade" e "impacto", geram para elas um conflito quase insolúvel, e acaba por torná-las, paradoxalmente, ainda mais dependentes dos grants dessas mesmas fundaçóes.

${ }^{26}$ Algo que atualmente já pode ser observado nas formaçóes universitárias em jornalismo e mesmo entre os profissionais que ainda trabalham em veículos de comunicação que não fazem parte do universo das nonprofits (DEMENECK, 2016, p. 64). 
teve como chefe Gavin Macfayden, jornalista investigativo de Londres, ex-membro do conselho consultivo da Pública), Panos London e Center for Investigative Reporting (Califórnia).

A profissional credita ao seu segundo período em Londres o conhecimento sobre o modelo de jornalismo non-profit, que foi aplicado à experiência da Pública. Além disso, sua passagem pelo exterior lhe rendeu o estabelecimento de uma série de contatos que foram mobilizados para possibilitar a criaçáo e funcionamento da ONG. A partir deste caso, é possível apreender tanto a variedade de rendimentos que a posse e reconversão de um capital internacional permite obter, quanto as lógicas concretas através das quais se realizam as operações de importação-exportação de modelos, concepções e práticas profissionais.

\section{O "furo do ano"27" e a criação da ONG}

Após retornar para o Brasil, Natalia Viana não voltou a trabalhar diretamente para nenhuma empresa jornalística, afirmando ter aprendido, em Londres, a fazer jornalismo "independente", vendendo suas reportagens para veículos diferentes, dentro e fora do país. Além dos "freelas" e reportagens independentes, também se dedicou à produção de livros-reportagem, todos voltados, direta ou indiretamente, para a temática dos direitos humanos.

Em novembro de 2010, estava cobrindo uma pauta na Amazônia quando recebeu um telefonema de uma jornalista com quem trabalhou no Center for Investigative Journalism, e foi convidada a participar de uma das séries de vazamentos de documentos sigilosos das embaixadas americanas promovidos pela organização Wikileaks ${ }^{28}$, que se insere naquilo que convencionou-se chamar de "ciberativismo". Ainda sem saber o teor da ligação, dadas as dificuldades de comunicação no interior do Pará, onde se encontrava, entra em contato com Gavin Macfayden, seu ex-chefe, para tentar obter maiores detalhes. Macfayden foi um dos diretores do Wikileaks e amigo próximo de Julian Assange (chegando inclusive a, juntamente com sua esposa, instituir um fundo que visava arrecadar dinheiro para a defesa de Assange contra as várias acusações das quais viria a ser alvo).

\footnotetext{
${ }^{27}$ Sobre a importância da lógica do "furo" no jornalismo, ver, entre outros, Marchetti (2002), Néveu (2006) e Champagne (1996 e 2016).

${ }^{28}$ ONG criada em 2006 por Julian Assange e sediada na Suécia. Publica em sua página postagens de fontes anônimas, documentos, fotos e informaçôes confidenciais, vazadas de governos ou empresas, sobre assuntos sensíveis.
} 
Diante do convite, volta para Londres, onde conhece Assange e trabalha durante seis meses, de modo "voluntário", nos documentos relativos ao governo brasileiro. "Idealismo" e "paixão" são palavras que ela utiliza para definir a atmosfera desse novo e ainda sigiloso trabalho (VIANA, 2011, s/p). Uma das tarefas atribuídas a ela foi a de escrever matérias em português e "conseguir parceiros confiáveis na mídia brasileira". Para a publicação das matérias oriundas das análises dos documentos no país, fez então uma parceria com o jornal Folha de S. Paulo, via Fernando Rodrigues $^{29}$, que já conhecia Gavin Macfayden desde meados de 2003, quando conjuntamente participaram de reunióes para a criaçáo da GIJN. Pouco depois, o jornal O Globo também integrou o "acordo de exclusividade" para a publicação das matérias relativas aos documentos ${ }^{30}$.

Tal como os trabalhos de Wagner (1998 e 2007) salientam, a posse de um capital social internacional é um elemento cada vez mais importante na gestão das carreiras. A inserção numa rede de sociabilidade cosmopolita permite adentrar espaços de atuação dificilmente acessíveis de outra forma. Assim, a participação de Natalia Viana no Wikileaks lhe rendeu notoriedade e reconhecimento profissional ${ }^{31}$, e a jornalista passou a ser chamada a dar inúmeras entrevistas e participar de debates. Aqui, é possível notar o quanto o capital internacional pode servir a parcelas dominadas de meios profissionais (DEZALAY e MADSEN, 2013) para afirmação e legitimação no contexto local ${ }^{32}$.

Um ano depois, e ainda com sua figura muito em evidência no espaço jornalístico, decide criar, junto com Marina Amaral, a Agência Pública, em parte aproveitando a publicização do seu trabalho para "catapultar" a ONG no meio profissional - projeto que já vinha sendo gestado desde o seu período na revista Caros Amigos.

${ }^{29}$ Um dos fundadores e ex-presidente da ABRAJI (2010-2011), ex-jornalista da Folha de S.Paulo e do portal de notícias UOL. Mestre em Jornalismo Internacional pela City University (Londres, 1987). Fundador e diretor de redação do portal Poder360. Membro do International Consortium of Investigative Journalists (ICIJ) desde 1999 e da Global Investigative Journalism Network (GIJN). Além disso, desde 2016 é membro do conselho consultivo do "Programa de Governança Fiscal" da Open Society Foundations. Benson (2018, p. 7) destaca o caráter interligado de diretorias de veículos de mídia e de fundações no contexto norte-americano.

${ }^{30}$ Maiores detalhes sobre a cobertura do Wikileaks no Brasil podem ser encontrados em Viana (2011 e 2013) e Rodrigues (2011).

${ }^{31}$ Recentemente, em 2018, Viana passou a compor a equipe de jornalistas do ICIJ.

${ }^{32}$ Sobre a mobilidade internacional de grupos dominados, ver Wagner (2007). 
"A primeira agência de jornalismo investigativo sem fins lucrativos do país" é criada em 2011, e coloca para si a "missão" de "produzir jornalismo independente, investigativo e inovador". Nas palavras de Natalia Viana: "a nossa lógica é uma lógica de ONG: a gente precisa convencer pessoas a nos apoiar. Até hoje, as pessoas que mais nos apoiaram foram grandes fundaçôes" (Entrevista com Natalia Viana, concedida em 28 jan. 2016).

Atualmente, a ONG conta com o financiamento de três fundaçóes internacionais, além de projetos de financiamento coletivo (crowdfunding): Fundação Ford (que financia a agência desde o seu início, em 2011), Open Society Foundations (desde 2015) e OAK Foundation (que financia programas de reportagem e fomento). Além destas, está a Climate and Land Use Alliance $\left(\mathrm{CLUA}^{33}\right)$, que financia projetos de cobertura da Amazônia. Por fim, a Pública ainda conta com o financiamento do Instituto Betty e Jacob Lafer, para projetos sobre "Justiça" e "Congresso".

As linhas gerais de atuação da ONG são pautadas pelo "fortalecimento do direito à informação", pela "qualificação do debate democrático" e pela "promoção" e "defesa intransigente" dos direitos humanos ${ }^{34}$. Alguns dos projetos especiais da agência foram direcionados para o desmatamento na Amazônia e para as violaçôes de direitos humanos e impactos de dois "megaeventos" esportivos (a Copa do Mundo de 2014, e as Olimpíadas de 2016). No entanto, além dos seus propósitos sociais e políticos, a Pública ainda advoga e milita pela causa da própria profissão (FRISQUE, 2010), dimensão que ficou mais evidente com a criação, em 2016, de um centro que busca discutir e apoiar iniciativas jornalísticas "independentes" no Brasil e na América Latina.

\section{Considerações finais}

O modelo de jornalismo investigativo sem fins lucrativos está diretamente ligado a concepções específicas do métier e recruta profissionais cujos perfis revelam um forte engajamento em "causas" sociais, com particular ênfase nos "direitos humanos". No entanto, esse engajamento mostra-se muito mediado pela condição profissional, ou seja, o que está em jogo é a promoção e defesa de "causas" via jornalismo (e, mais especificamente, jornalismo investigativo), algo que pode ser

\footnotetext{
33 A CLUA é o resultado de uma aliança de quatro fundaçóes: Fundação Ford, ClimateWorks Foundation, The David and Lucile Packard Foundation e Gordon and Betty Moore Foundation.

${ }^{34} \mathrm{O}$ caráter "intransigente" dessa defesa permite situar as jornalistas da ONG no campo de atuação daqueles que Becker (2008, p. 153-168) chama de "empreendedores morais".
} 
observado também em ONGs relacionadas ao mundo do direito (ENGELMANN, 2006b). É o serviço à causa profissional, em primeiro lugar, que parece condicionar a relação com as demais formas de engajamento. Nesse sentido, é interessante notar que todas as três jornalistas fundadoras da ONG Pública foram agraciadas, em diferentes momentos e por diferentes trabalhos, com o prêmio Vladimir Herzog de Anistia e Direitos Humanos.

Embora não seja um indicador unívoco (WAGNER, 1998), as viagens para o exterior, o aperfeiçoamento em outros idiomas e as experiências diversas adquiridas na Europa demonstram ter um peso, ainda que bastante variável, nas concepçóes profissionais e na estruturação das carreiras, com particular intensidade no caso da jornalista Natalia Viana.

O desenvolvimento internacional de organizações sem fins lucrativos (com ou sem financiamento de grandes fundações) voltadas para a produção de jornalismo investigativo levanta a questâo - em aberto - das condiçôes de possibilidade e dos limites da constituição de uma espécie de "internacional dos jornalistas" (ou, de modo mais amplo, de uma "internacional da denúncia"), isto é, de um espaço transnacional composto, ao mesmo tempo, por relaçóes de cooperação e concorrência entre agentes e instituições diversos, estruturado em torno de "denúncias", "vazamentos" e/ou "grandes investigações" em escala pretensamente global - algo próximo daquilo que Dezalay e Garth (2002, p. 208) chamam de "redes internacionais de elites profissionais", inseridas em um "mercado internacional do ativismo".

João Gilberto do Nascimento Lima é Doutorando em Ciência Política pela Universidade Federal do Rio Grande do Sul. E-mail: joaogilberto@ymail.com.

\section{Referências}

ALVES, Rosental Calmon. From lapdog to watchdog: the role of the press in Latin America's democratization. In: DE BURGH, Hugo (Org.). Making journalists. Abingdon: Routledge, 2005, p. 181-202. 
ASSIS, Evandro de; CAMASÃO, Leonel; SILVA, Mariana Rosa; CHRISTOFOLETTI, Rogério. Autonomia, ativismo e colaboração: contribuiçôes para o debate sobre a mídia independente contemporânea. Revista Pauta Geral, v. 4, n. 1, p. 3-20, 2017.

BECKER, Howard. Outsiders: estudos de sociologia do desvio. Rio de Janeiro: Jorge Zahar Ed., 2008. BENSON, Rodney. Can foundations solve the journalism crisis? Journalism. v. 19, n. 8, p. 1-19, 2018.

BOURDIEU, Pierre. A produção da crença: contribuição para uma economia dos bens simbólicos. In: A produção da crença: contribuição para uma economia dos bens simbólicos. Porto Alegre: Zouk, 2006, p. 19-111.

A representação política: elementos para uma teoria do campo político. In:

poder simbólico. Rio de Janeiro: Bertrand Brasil, 2007, p. 163-207.

A economia dos bens simbólicos. In: . Razôes práticas: sobre a teoria da ação:

Campinas, SP: Papirus, 1996, p. 157-197.

. Sobre a televisão. Rio de Janeiro: Jorge Zahar Ed., 1997.

BRIQUET, Jean-Louis; GARRAUD, Philippe. Introduction. In: BRIQUET, Jean-Louis; GARRAUD, Philippe (Dir.). Juger la politique. Entreprises et entrepreneurs critiques de la politique. Rennes: PUR, 2001, p. 13-21.

CHAMPAGNE, Patrick. Formar a opinião: o novo jogo político. Petrópolis, RJ: Vozes, 1996.

L'étude des médias et l'apport de la notion de champ. In: PINTO, Éveline (Dir.). Pour une

analyse critique des médias. Le débat public en danger. Bellecombe-en-Bauges: Éditions du Croquant, 2007, p. 39-53.

La double dépendance. Sur le journalisme. Paris: Raisons d'agir, 2016.

CHAMPY, Florent; ISRAËL, Liora. Professions et engagement public. Sociétés Contemporaines, n. 73, p. 7-19, 2009.

CHUPIN, Ivan; NOLLET, Jérémie. Jalons pour une sociologie historique des interdépendances du journalisme à d'autres univers sociaux. In: CHUPIN, Ivan; NOLLET, Jérémie (Dir.). Journalisme et dépendances. Paris: L'Harmattan, 2006, p. 15-36.

CORADINI, Odaci Luiz. Elites culturais e concepçóes de política no Rio Grande do Sul entre as décadas de vinte e sessenta. Relatório de pesquisa para o CNPq. Porto Alegre, 1998.

DEMENECK, Ben-Hur. Jornalismo transnacional: prática, método e conceito. 2016. 236 f. Tese (Doutorado em Ciências da Comunicação) - Programa de Pós-Graduação em Ciências da Comunicação, Universidade de São Paulo, São Paulo, 2016.

DEZALAY, Yves; GARTH, Bryant G. La mondialisation des guerres de palais. La restructuration du pouvoir d'État en Amérique latine, entre notables du droit et "Chicago Boys". Paris: Seuil, 2002.

DEZALAY, Yves; MADSEN, Mikael Rask. Espaços de poderes nacionais, espaços de poderes internacionais: estratégias cosmopolitas e reprodução das hierarquias sociais. In: CANÊDO, Letícia; TOMIZAKI, Kimi; GARCIA Jr., Afrânio Raul (Orgs.). Estratégias educativas das elites brasileiras na era da globalização. São Paulo: Hucitec-Fapesp, 2013, p. 23-52.

ENGELMANN, Fabiano. Sociologia do campo jurídico: juristas e usos do direito. Porto Alegre: Sergio Antonio Fabris Ed., 2006a.

Internacionalização e ativismo judicial: as causas coletivas. Lua Nova, n. 69, p. 123-146, $2006 \mathrm{~b}$. 
FERRON, Benjamin. Les médias alternatifs entre luttes de définition et luttes de (dé)légitimation. Les enjeux de l'information et de la communication, $8^{e}$ Colloque France-Brésil, Grénoble, 2006.

. Le journalisme alternative entre engagement et distanciation. Les strategies médiatiques des mouvements sociaux dans la "bataille de Cancún" contre l'OMC (2003). In: LÉVÊQUE, Sandrine; RUELLAN, Denis (Orgs.). Journalistes engagés. Rennes: PUR, 2010, p. 109-126.

FORTES, Leandro. Jornalismo Investigativo. São Paulo: Contexto, 2005.

FRISQUE, Cégolène. Des militants du journalisme? Les journalistes “critiques" comme militants de l'autonomie professionnelle. In: LÉVÊQUE, Sandrine; RUELLAN, Denis (Orgs.). Journalistes engagés. Rennes: PUR, 2010, p. 145-164.

GARRAUD, Philippe. Les nouveaux juges du politique en France. Critique internationale, v. 3, p. 125-139, 1999.

GUILHOT. Nicolas. Os profissionais da democracia em ação. In: LINS, Daniel; WACQUANT, Loïc (Orgs.). Repensar os Estados Unidos: por uma sociologia do superpoder. Campinas: Papirus, 2003, p. 209-238.

HUBÉ, Nicolas. La "professionnalisation" sous contrainte de la presse alternative. L'introduction d'une hiérarchie à Libération et à la Tageszeitung. In: LÉVÊQUE, Sandrine; RUELLAN, Denis (Orgs.). Journalistes engagés. Rennes: PUR, 2010, p. 91-107.

HUNTER, Mark. Le journalisme d'investigation. Paris: PUF, 1997.

KAPLAN, David E. Global Investigative Journalism: Strategies for Support. A Report to the Center for International Media Assistance (CIMA), 2013.

KUCINSKI, Bernardo. Jornalistas e revolucionários: nos tempos da imprensa alternativa. São Paulo: Página Aberta, 1991.

LAGROYE, Jacques. Les processus de politisation. In: LAGROYE, Jacques (Dir.). La politisation. Paris: Belin, 2003, p. 359-372.

LÉVÊQUE, Sandrine. Introduction. In: LEVÊQUE, Sandrine; RUELLAN, Denis (Orgs.). Journalistes engagés. Rennes: PUR, 2010, p. 9-16.

MARCHETTI, Dominique. Le “journalisme d'investigation”. Genèse et consécration d'une spécialité journalistique. In: BRIQUET, Jean-Louis; GARRAUD, Philippe (Dir.). Juger la politique. Entreprises et entrepreneurs critiques de la politique. Rennes: PUR, 2001, p. 167-191.

. Les sous-champs spécialisés du journalisme. Réseaux, v. 1, n. 111, p. 21-55, 2002.

Quand la santé devient médiatique: les logiques de production de l'information dans la presse. Grenoble: PUG, 2010.

MATOS, Carolina. Jornalismo e política democrática no Brasil. São Paulo: Publifolha, 2008.

MERLINO, Tatiana. Merlino x Ustra: memória de um tempo não vivido. São Paulo: Agência Pública de Jornalismo Investigativo, 2011. Disponível em: <https://apublica.org/2011/07/merlino-x-ustramemoria-de-um-tempo-nao-vivido/>. Acesso em: 17 jul. 2018.

NASCIMENTO, Solano. Os novos escribas: o fenômeno do jornalismo sobre investigaçôes no Brasil. Porto Alegre: Arquipélago Editorial, 2010.

NEVEU, Érik. Sociologia do jornalismo. São Paulo: Ediçóes Loyola, 2006.

PAULINO, Fernando Oliveira; XAVIER, Aline Cristina Rodrigues. Jornalismo sem fins lucrativos: transição, sustentabilidade e independência. Revista Comunicação Midiática. Bauru-SP, v. 10, n. 1, 
p. 154-168, 2015. Disponível em: <http://www2.faac.unesp.br/comunicacaomidiatica/ index.php/comunicacaomidiatica/article/view/575>. Acesso em: 10 ago. 2018.

PÉCAUT, Daniel. Os intelectuais e a política no Brasil: entre o povo e a nação. São Paulo: Ática, 1990.

PEREIRA FILHO, Francisco José Bicudo. Caros Amigos e o resgate da imprensa alternativa no Brasil. São Paulo: Annablume, 2004.

PETRARCA, Fernanda Rios. O jornalismo como profissão: recursos sociais, titulação acadêmica e inserção profissional dos jornalistas no Rio Grande do Sul. 2007. 308f Tese (Doutorado em Sociologia) - Programa de Pós-Gradução em Sociologia, UFRGS, 2007.

RIBEIRO, José Hamilton. Com seu rigor e generosidade, Sérgio de Souza foi um mártir do jornalismo. São Paulo: Folha de S.Paulo, 2018. Disponível em: $<$ https://www1.folha.uol.com.br/ilustrissima/2018/01/1951712-com-seu-rigor-e-generosidadesergio-de-souza-foi-um-martir-do-jornalismo.shtml>. Acesso em: 14 ago. 2018.

RODRIGUES, Fernando. Folha e WikiLeaks: como se estabeleceu o contato. São Paulo, Folha de S.Paulo, 2011. Disponível em: <https://www1.folha.uol.com.br/fsp/ilustrissima/il0602201107.htm>. Acesso em: 15 ago. 2018.

SCHUDSON, Michael. Descobrindo a notícia: uma história social dos jornais nos Estados Unidos. Petrópolis, RJ: Vozes, 2010.

SEQUEIRA, Cleofe Monteiro de. Jornalismo investigativo: o fato por trás da notícia. São Paulo: Summus, 2005.

SIMÃO, Guilherme de Oliveira. Como financiar o jornalismo investigativo: o caso das organizaçóes sem fins lucrativos. Um estudo de caso sobre a Agência Pública. In: II Seminário de Pesquisa em Jornalismo Investigativo, São Paulo, 2015.

SOUZA, Candice Vidal. Repórteres e reportagens no jornalismo brasileiro. Rio de Janeiro: Editora FGV, 2010.

VIANA, Natalia. Como conheci Julian Assange e como o Wikileaks veio parar no Brasil. São Paulo, Agência Pública de Jornalismo Investigativo, 2011. Disponível em: $<$ https://apublica.org/2011/07/como-conheci-julian-assange-e-como-o-wikileaks-veio-parar-obrasil/>. Acesso em: 09 mar. 2016.

. O Wikileaks e as batalhas digitais de Julian Assange. In: ASSANGE, Julian et al. (Orgs.). Cypherpunks: liberdade e o futuro da internet. São Paulo: Boitempo, 2013, p. 9-18.

WAGNER, Anne-Catherine. Les nouvelles élites de la mondialisation. Une immigration dorée en France. Paris: PUF, 1998.

. Les classes sociales dans la mondialisation. Paris: La Découverte, 2007.

WAGNER, Anne Catherine; RÉAU, Bertrand. Le capital international: un outil d'analyse de la reconfiguration des rapports de domination. In: SIMÉANT, Johanna (Dir.). Guide de l'enquête globale en sciences sociales. Paris: CNRS Éditions, 2015, p. 33-46.

Texto recebido em 15 de agosto de 2018. Aprovado em 31 de outubro de 2018. 